\title{
Characterisation, Evaluation and Clinical Significance of Latent HIV-1 Reservoirs and Therapeutic Strategies for HIV Eradication
}

\author{
James Williams ${ }^{1}$, Sarah Fidler ${ }^{2}$ and John Frater ${ }^{1,3}$ \\ 1 Peter Medawar Building for Pathogen Research, Nuffield Department of Medicine, \\ University of Oxford, Oxford \\ 2Division of Medicine, Wright Fleming Institute, Imperial College, St. Mary's Hospital, \\ Norfolk Place, Paddington, London, United Kingdom \\ ${ }^{3}$ Oxford NIHR Comprehensive Biomedical Research Centre, Oxford \\ United Kingdom
}

\section{Introduction}

HIV induces persistent infection and, despite improvements in mortality and morbidity conferred by Highly Active Antiretroviral Therapy (HAART), there is currently no cure [1]. The immune system controls HIV only partially, and plasma HIV and proviral DNA can be detected from acute primary infection to end-stage AIDS [2]. More than 99\% of HIV replication has been demonstrated in activated and infected CD4+ T-cells [3]. These are the very cells that are instrumental in the clearance of virus through the host's adaptive immune response. Gradually, throughout the course of infection, repeated rounds of CD4+ T cell infection lead to an overall and marked decrease in the total number of CD4+ T cells [4] and this has been linked to the clinical manifestations of HIV disease [5]. HIV-1 replicates rapidly in infected patients, with a virion half-life of less than 6 hours in plasma [6], and a half-life of 1-2 days in proliferating infected cells [7] [8] [9], corresponding to the short-lived population that produces most of the HIV-1

The major problem with eradication of HIV lies with the existence of a pool of latently infected cells. Retroviral latency occurs when a provirus infects and integrates into the genomic DNA of its target cell, but is transcriptionally silent [10]. These cells are able to persistently produce infectious HIV virions when activated, even from patients on highly active antiretroviral therapy (HAART), and are a potential source of rebounded virus after HAART treatment is interrupted [3]. There are myriad cells and tissue types in which HIV can integrate, and it is at these sites that the long-term preservation of replication-competent HIV can occur [11].

Infectious virus within HIV reservoirs has a longer half life than the virus in cells where there is active viral replication [12]. The half life of the viral reservoir has been estimated at 43.9 months during three years of HAART, [13] and 44.2 months whilst on seven years of HAART [14]. Thus, it had been estimated to take possibly as long as 60 years to eradicate the virus using HAART alone [13]. In other studies, the reservoir half life in patients with optimal suppression of viral replication was estimated to be as little as 6 months [15] [16]. 
HAART usually consists of a combination of at least three antiretroviral drugs, typically two nucleoside analogue reverse transcription inhibitors and a third drug, either a protease or non nucleoside reverse transcriptase inhibitor [17-18]. There are currently 22 licensed antiretroviral drugs [19] which fall into the following categories; Nucleoside reverse transcription inhibitors (NRTI), non-nucleoside reverse transcriptase inhibitors (NNRTI), protease, integrase, entry and maturation inhibitors. Antiretroviral drug therapy (ART) has led to a significant decline in morbidity and mortality in HIV-1 infected individuals in the developed world [20], with mortality in 1255 studied patients falling from 29.4 per 100 person-years in the first quarter of 1996 to 8.8 per 100 person years in the second quarter of 1997 [21]. In this study, Mycobacterium avium complex disease, and cytomegalovirus retinitis incidence declined from 21.9 per 100 person-years in 1994 to 3.7 per 100 person-years in mid-1997. The actual HAART regime was shown not to impact on residual viremia [22]

There is contradictory evidence supporting the use of HAART in early, or 'primary', HIV infection. In one study when HAART was initiated in patients during primary HIV infection, the formation of a latently infected CD4+ T-cell reservoir was not inhibited, despite the control of plasma HIV viremia levels [23]. However, in another study, 5/32 patients who received very early and prolonged (77 month) HAART exhibited sustained immuno-virological control of HIV, after treatment interruption. This subset of patients did not exhibit the genetic characteristics of elite controllers, so were termed 'post treatment controllers', a distinct population. The viral reservoir amongst the 'post treatment controllers' was very low and stable, suggesting that early therapy could cause a reduction in the viral reservoir [24], perhaps to a point where the immune system can control HIV infection without HAART. The rapid initiation of antiretroviral drugs after initial HIV infection was therefore hypothesised to prevent damage of the immune system and minimise the size of the latent reservoir [25].

However, despite HAART regimes having reduced the frequency of HIV-infected cells to fewer than 1 cell per $10^{6}$ resting CD4+ T-cells [13-14, 26], when HAART is interrupted, in most cases, rapid viral rebound from the latent HIV reservoir still occurs [27]. The life expectancy of patients on HAART is still less than that for uninfected people [28]. There is also morbidity in patients on HAART that is not explained by drug toxicities, mostly due to cardiovascular and metabolic complications [29-30], as well as renal and hepatic toxicities, osteoporosis, dementia and ageing [31]. Also, the logistics of providing HAART to developing regions are currently extremely challenging [32]. Collectively, these data show that HAART mediated eradication of HIV is unlikely and that there is a real need for new therapies if the goal of HIV eradication is ever to be achieved.

\section{HIV-I latency}

Despite the wealth of experimental evidence to suggest that productive HIV-1 infection occurs in activated CD4+ T-cells [33], there are many points at which integration of HIV into the genome, and thus latency can be blocked. The presence of small nucleotide pools [34] coupled with an inability to import the pre-integration complex into the nucleus [35] results in inefficient reverse transcription of the HIV genome and a latent viral phenotype [36-37]. However, this pre-integration latency is a labile form of latency and rapidly decays on HAART, and is unlikely to contribute to residual or rebound virus [36, 38-39].

In post integration latency, HIV-1 must infect an activated CD4+ T-cell, so that efficient reverse transcription and nuclear import can occur, leading to the integration of HIV-DNA 
into the host genome. However, for a latent phenotype to emerge, the infected cell must then return to a quiescent (G0) or resting state. Generally, HIV-infected activated CD4+ T cells die due to the cytopathic effect of virus, or from host-mediated immune killing, however, some infected activated CD4+ T-cells may survive just long enough to revert to the resting state [40]. The fact that resting CD4+ T-cells were shown to contain integrated HIV provirus [41] supports this theory. Subtle differences in HIV integration sites between activated and resting CD4+ T-cells were discovered through 454-pyrosequencing, with insertion into actively transcribing gene sites most favoured, although in resting CD4+ Tcells, integrated DNA was more commonly found in regions suboptimal for the expression of proviral genes [42].

\section{Characterisation and evaluation of HIV-1 reservoirs}

When HAART is initiated, four plasma virus decay phases have been described. Firstly, there is an initial rapid decline in plasma virus, with a half-life of around 2 days [6, 8, 43-44]. Treatment with ABT-538, an HIV-1 protease inhibitor, caused an exponential decrease in plasma HIV-1, with an estimated half life of $2.1+/-0.4$ days, and a substantial increase in CD4 lymphocyte counts [7]. This initial decline is thought to be due to the elimination of short-lived HIV-infected cells of the lymphocyte lineage, including activated CD4+ lymphocytes, due to the cytopathic effect of HIV, or through immune-mediated destruction [1]. A biphasic decay in plasma viremia was seen in 7 acute seroconverters who received HAART shortly after initial symptoms. The first phase was thought to reflect the loss of virus from productively infected cells and the second phase, loss of virus from latently infected cells [45]. However, many studies have shown that the HIV viral reservoir need not be restricted to that of the lymphocyte lineage and virus has been discovered in a vast array of different cell types, discussed later. The source of the virus contributing to the third and fourth phases is less clear, but may include macrophages, tissue sanctuary sites and sporadic activation of latently infected memory lymphocytes.

\subsection{The resting CD4+ T-cell reservoir}

A major HIV reservoir is thought to be latently infected resting memory CD4+ T-cells [26, 46]. Persistently infected resting CD4+ T-cells have been isolated from peripheral blood samples of HIV-infected patients whose HAART regimes resulted in very low plasma viremia levels [47]. Another study showed that the activation of CD4+ T-cells with anti-CD3 and anti-CD28 antibodies and depletion of CD8+ T-cells from six patients who maintained undetectable viral levels under HAART for 2 years, could release PBMC-derived replication-competent virus [48]. In a study of 22 successfully HAART treated patients, replication-competent virus was isolated from infected CD4+ T-cells, although the frequency of these latently infected cells was low - around 0.2 to 16.4 per $10^{6}$ cells. While patients were on therapy, this reservoir of latently infected CD4+ T-cells was shown not to decline with time [46]. In another study, the CD4+ T-cells isolated from all 13 HAARTreceiving patients with undetectable plasma viremia carried integrated proviral HIV-DNA, and on cellular activation, were shown to release viable virus [26]. This latent viral reservoir in memory T-cells was shown to be established very early in HIV infection [23] and the activation of these resting $\mathrm{T}$ cells by proinflammatory cytokines induced in vitro release of infectious HIV [49]. 
Replication-competent latent provirus has been mostly recovered from patients on suppressive HAART in resting (CD45RO) CD4+ T-cells, although low levels of virus have been discovered in resting naïve (CD45RA) CD4+ T-cells [10]. Since the infection of naïve Tcells is a rare event, most resting CD4+ T-cells will have been infected with HIV when they were in a prior activated state, suggesting that these infected activated CD4+ T-cells can revert back to a naïve state, conducive for HIV latency [50]. Thymocytes, a haematopoietic progenitor cell type found in the thymus of adults and children naturally develop into naïve T-cells in the T-lymphocyte developmental pathway, so the presence of proviral DNA in naïve T-cells could be explained by latently infected thymocytes developing into naïve Tcells, which still contain the latently infected proviral DNA [51].

A recent study has identified subsets of CD4+ T-cells as distinct reservoir locations. Central memory (TCM) and Transitional memory T cells (TTM) were found to constitute major HIV reservoirs. In patients who had started HAART early, the viral reservoir was located in the long-lived TCM cells. Cytotoxic T cell killing, apoptosis and cytopathic viral effects were hypothesised to reduce this reservoir, as TCM cells may be able to mount an antigeninduced response. However, in patients who started therapy late, the reservoir was mostly present in TTM cells, attributable to greater CD4+ T-cell proliferation. TTM cells have been shown to proliferate at low levels, through IL-7-induced mitosis and thus may be able to act as a continuously replenishing reservoir [52].

\subsection{Macrophages, monocytes and partially activated T-cells}

The second phase of decline in plasma virus levels on HAART [6] has an estimated half life in the range of 1-4 weeks, and is thought to represent virus present in infected macrophages and monocytes, which are known to be more resistant to the cytopathic effects of HIV infection [53-54] and which, once terminally differentiated, have a turnover rate of approximately two weeks [55]. Replication competent HIV has been isolated from peripheral blood monocytes of HAART-treated patients [53] and infected monocytes have been isolated from patients on effective HAART [56]. There is evidence for HIV replication in vivo in CD14+ monocytes [57], infectious HIV has been shown to assemble in late endosomes in primary macrophages [58], and virions persisting in monocyte-derived macrophages have been shown to retain infectivity for weeks [59], thus suggesting possible new mechanisms for HIV persistence. However, the theory that macrophages, monocytes or partially activated CD4+ T-cells could represent a separate source of virus is disputed, since in two studies using Raltegravir, an integrase inhibitor, no second phase decay kinetics on treatment were observed [60-61]. It is also possible that this second decay phase in plasma viremia levels could also reflect the destruction of other viral reservoirs, for example the release of virus after activation of partially activated T-lymphocytes [40].

By extrapolating the first and second phase decay kinetics, it was initially suggested that HAART alone may be able to eradicate virus from infected individuals, since virus levels could fall to below detectable levels after 2 months of therapy [44]. However, this prediction was based on the assumption that HAART completely inhibits all viral replication and that no viral reservoirs with a half life longer than a few days exist in infected patients [62]. Despite the initial thought that HIV could be eradicated with HAART [6], this has shown to be false extremely unlikely, since other reservoirs with longer half-lives have been detected. 


\subsection{Follicular dendritic cells}

Follicular Dendritic cells (FDC) have been suggested to contribute to the second and third phase decay in plasma viremia, since infectious virus [63] binds through the viral envelope proteins to DC-SIGN receptors, expressed on the FDC cell surface [64]. This more prolonged third decay phase has been estimated to have a half-life of around six months [43, 65], although a half-life of 30 months during HAART was estimated in another study [66], and mathematical modelling studies have shown HIV:FDC interactions to persist for years, despite effective HAART [67]. Through phylogenetic analysis of the HIV that interacts with FDCs isolated from 2 out of 4 patients, the virus present was similar to the virus isolated 22 months earlier, which suggests long-term FDC sequestration of replication-competent HIV [68]. However, other studies have shown DC-SIGN being unable to protect against virion degradation, since loss of HIV infectivity was reported over a course of hours [69].

\subsection{Other HIV reservoirs}

\subsubsection{Gut - Associated Lymphoid Tissue (GALT)}

There is evidence for the presence of HIV-1 DNA and RNA in the duodenum, ileum, colon and rectum, from gut biopsy studies. The concentration of HIV-1 DNA increases from duodenum to rectum [70] and there is evidence for ongoing residual HIV replication in the ileum [71]. Mucosal lymphoid tissues may be an important reservoir outside of the peripheral blood for residual HIV viremia whilst patients are on HAART, since the GALT contains the highest level of activated CD4+ T-cells, which can support HIV replication [72]. In SIV infection, the gastrointestinal (GI) tract was shown to be a major site of CD4+ T-cell depletion and viral replication [73], and viral replication was found to be disproportionally higher in the GALT than in the blood [74]. Rapid accumulation and early establishment of HIV-1 in the lymphatic system has also been observed after HIV infection [75].

\subsubsection{CD34+ multipotent hematopoietic progenitor cells}

CD34+ multipotent haematopoietic progenitor cells have shown to be permissive to HIV infection, but it is not know whether a latent phenotype can emerge or whether this potential reservoir can contribute to persistent viremia seen in patients on HAART [76]. Since HIV-infected monocytes were discovered in HAART treated patients, and since their short halflife in the blood, this could also be evidence that monocyte precursor cells were infected [56].

\subsubsection{Mast cells}

Mast cells from human tissue have been shown to be an inducible reservoir of persistent HIV infection [77].

\subsubsection{Urogenital tract}

Through the longitudinal analysis of gp120 in five acute HIV seroconverters, it was discovered that the HIV populations present in genital secretions were different to that extracted from blood plasma. This indicated that the male urogenital tract could act as a separate reservoir to resting CD4+ T-cells [78]. HIV has also been found in seminal fluid, T cells and macrophages isolated from the seminal fluids of patients of HAART [79-80]. 


\subsubsection{Central Nervous system (CNS)}

Different HIV sub-populations have been isolated from the CNS and peripheral blood. CNS HIV was less able to infect T-cell lines, modulate CD4 antigen expression in infected cells and neutralise serum, as well as having reduced cytopathogenicity, whereas blood-isolated HIV replicated better in T-cell and glioma cell lines [81]. HIV has been shown to persist in nervous tissue, such as microglia, astrocytes and in cells contained within the cerebrospinal fluids [82-84].

\subsubsection{Kidney}

A possible HIV reservoir exists in tubular epithelial kidney cells [85], as viral replication, through hybridisation studies, has been detected in patients on suppressive HAART [86-87]. In the study by Marras et al, kidney cells were shown to be permissive for viral replication and represented a phylogenetically distinct HIV reservoir.

\subsection{Residual viremia}

After around 12 to 16 weeks of HAART, the levels of HIV RNA fall below the limit of detection of many clinical assays (less than 20-50 RNA copies/ml) [88]. Following this, slow viral decay, with a half life of between 39 and infinite weeks, reflects the release and clearance of HIV contained within the latently infected lymphocyte reservoir - the third and fourth decay phases of plasma HIV decline [89-90]. However, through the use of low copy viral load assays [91], most (80\%) patients on HAART treatment have detectable persistent viraemia [92-93]. Palmer et al demonstrated this viraemia to persist at an average level of 0.781 copies $/ \mathrm{ml}$ in 15 patients on HAART treatment using a low copy viral load assay, despite having clinically undetectable viral RNA levels using standard clinical assays. Viremia was shown to persist at low levels for at least 7 years in patients on suppressive HAART [94].

The single copy assay was used to analyze longitudinally sampled plasma HIV RNA levels in 40 patients enrolled in the Abbott M97-720 trial [91] and 77\% of patient samples were found to have detectable low level viremia. In another study using the single copy analysis, $80 \%$ of patients on suppressive HAART had $>1$ viral RNA copy (with a median of 3.1 copies) per $\mathrm{ml}$ of plasma with no decrease in plasma viremia up to 60-110 weeks after starting therapy [22]. Kinetic examinations of viral decay revealed a two-stage decline in plasma RNA levels from HAART treated patients, sampled at 60 and 384-week intervals. This suggested that two cell compartments could potentially give rise to the low level decline of HIV persistent viremia. The first compartment represents a productively infected cell type from which virus is produced and released from cells, but is not able to re-infect naïve cells due to the inhibitory nature of HAART. This causes a decline in virus production over time. The second compartment reflects a reservoir of latently infected cells where the production of virus remains stable for at least seven years [94].

A novel ultrasensitive isothermal transcription-mediated amplification (TMA) assay was used to identify HIV-1 RNA levels in patient plasma samples over 12 years. Virus and antibody levels whilst on HAART was shown to decrease during the first 12 months, then remained stable with a seemingly infinite half-life in a steady-state 'set point' during HAART combination therapy [95].

It is not known whether the residual viremia that is seen in plasma samples of long-term HAART-treated patients reflects replication-competent virions. However, a study using 
recombinant viral clones isolated from a single patient show that viable virus can be isolated from the plasma of patients on HAART [96].

\subsubsection{Source of residual viremia}

The cellular and anatomical source of this residual virus also remains unknown. A phylogenetic analysis comparing residual plasma virus and CD4+ T-cell associated virus revealed two genetically distinct viral populations, in four out of five patients [96]. It was also shown that viral plasma sequences during HAART treatment and scheduled treatment interruption (STI) studies were both produced from a compartment, different to that of the circulating CD4+ T-cells, suggesting residual plasma virus production from a cellular source, yet to be identified, and that may contribute to the rapid viral rebound seen in patients undergoing STI studies [96]. Residual viremia was demonstrated to be genetically distinct from proviral DNA isolated from monocytes, unfractioned PBMCs and resting and activated CD4+ T-cells, where the viruses belonged to the same population, also suggesting that residual viremia is produced from a cellular source that is not the CD4+ T-cell compartment [97].

On analysis of HIV Pol gene sequences from plasma virus and resting CD4+ T-cell proviral DNA from HAART-treated patients, the plasma viremia in most patients was not related to, and was rarely found in resting CD4+ T-cells, but instead was dominated by a 'small number of invariant clones' [98]. Since the 'predominant plasma sequences' did not evolve whilst patients remained on HAART treatment, the persistent residual viremia was concluded to just arise from the prolonged production of a small number of viral clones in a compartment different to that of the resting CD4+ T-cell. Shen and Siliciano hypothesised that rare HIV infection of and integration into the DNA of a cell type with proliferative capacities, for example stem cells or macrophage/monocyte lineage progenitor cells, could give rise to these predominant plasma clones. The infected cell can then proliferate, copying the viral genome without error induction and thus give rise to myriad differentiated progeny cells, all that are latently infected and all that can potentially contribute to residual viremia [19].

\subsubsection{Sporadic release of latent virus from reservoirs}

There is much debate as to whether the persistent, residual viremia observed in patients under HAART is produced from new cycles of viral replication or from sporadic release of latent virus [19]. Drug regime and treatment intensification had no effect on reducing this residual viraemia in one study [99], and this may be because HAART only blocks new rounds of HIV infection but does not prevent sporadic HIV release from the latently infected cell reservoirs. Variation in residual viremia levels between patients correlates with the preHAART treatment viral loads, suggesting HIV is spontaneously and sporadically released from the latent reservoirs [94]. Also, it was suggested that HAART drugs may suppress HIV viremia to a baseline level, proportional to the initial extent of the pre-therapy latent reservoir, because of similar observed levels of residual viremia in patients with varying expected levels of anti-HIV activity [91].

The low level-viremia seen in HAART-treated adults and children was shown to be related to pre-HAART virus, with no evidence of drug-resistant mutation selection. Since there was no virus evolution, it has been suggested that no residual virus replication was occurring [100]. A novel RT-PCR method for genotyping the HIV-1 protease gene at low viral loads (5 copies $/ \mathrm{ml}$ ) revealed that children who began successful inhibitory HAART soon after birth, 
also did not exhibit drug-resistance mutations to the protease inhibitor nelfinavir and the virus resembled that found in resting CD4+ T-cells [101]. A longitudinal study has again shown lack of evolution in residual viraemia through analysis of drug resistance mutations in reverse transcriptase and protease sequences from eight patients who maintained undetectable viraemia for 15 months [102]. Also, no viral evolution was observed between polymerase gene sequences in patients on HAART, isolated from longitudinally sampled plasma and CD4+ T-cells [98].

A number of people receiving HAART experience viral 'blips' or increases in plasma viral load to detectable levels. These viral blips have been postulated to be because of emerging drug resistant viruses [103], [104]. However, it was discovered that these viral blips do not contain new drug resistant mutations, which supports the spontaneous viral release model [105] and most 'blips' are within expected statistical fluctuations [19].

\subsubsection{On-going replication?}

Despite evidence of no viral evolution whilst on HAART, some studies that assess other parameters of viral replication suggest that there may be on-going replication. For example, inflammatory markers (hsCRP, Il-6, d-dimer and Cystatin-C) are elevated in treated HIV patients, compared to untreated, suggesting low grade immune activation, despite therapy [106].

Evidence of continued viral replication was gleaned in a study whereby the PBMCs of 138 patients on suppressive HAART who have undetectable plasma HIV levels, were examined for intracellular HIV-RNA. In all 138 patients, intracellular HIV-RNA was detected, which in the absence of plasma HIV-RNA represents newly synthesised RNA, and provides evidence for new rounds of viral replication while on HAART therapy [107]. New rounds of HIV replication were discovered in the lymph nodes and PBMCs of 10 patients on up to 52 weeks of HAART, even after 1 year, and where there was incomplete inhibition of viral replication, resistance mutations emerged [108]. In two patients, sequence evolution was demonstrated in PBMCs, and in one patient, there was evidence of persistent replication but no viral drug resistance in the lymph nodes [15]. In another study comparing the HIV-1 C2V3 envelope regions, between baseline and residual virus in six patients after two years of HAART, viral evolution was observed in half of the patients and correlated with incomplete viral suppression indicated by the speed of initial virus decline and intermittent rebound events, whilst on HAART [109]. Also, there was persistent HIV transcription in PBMCs from patients on HAART, based on DNA and mRNA analysis on longitudinal samples from 5 men [110].

Ongoing HIV replication was discovered through four viral genetic analyses in a subset of children, over 5.1 years of HAART [111]. The presence of unintegrated proviral DNA seen in one study [26] could be evidence of ongoing viral replication in patients on HAART. Also, 2LTR circles were seen in the CD4+ T-cells of patients receiving HAART. This viral DNA is formed through the self-ligation and circularisation of proviral HIV DNA by host cell ligase enzymes. Since 2-LTR circles are thought to have a short half life, this could be evidence of ongoing viral replication [112], however, the half-life of LTR circles has been shown to be considerably longer than previously thought and may not always be indicative of recent infection [113-114].

Low levels of viral replication were shown to persist in patients receiving HAART, which could replenish the viral reservoir, thus increasing its half-life [16]. In a cohort of patients, aviremic under HAART treatment for up to 9.1 years, higher levels of HIV proviral DNA 
were discovered in their activated CD4+ T-cells compared to resting CD4+ T-cells. There was phylogenetic evidence for cross infection between resting and activated cells, which suggests there is an ongoing reactivation of latently infected CD4+ T-cells, potentially causing further infection of virus into activated CD4+ T-cells. It was suggested that these events may contribute to the replenishment of the CD4+ T-cell reservoir, and may 'reset' the half-life of the latently infected resting CD4+ T-cells [115]. In the GALT of HAART treated patients, who were aviremic for up to 9.9 years, incomplete recoveries of CD4+ T-cells were demonstrated. Interestingly, higher frequencies of HIV infection were demonstrated in the gut, compared to in PBMCs and cross infection between the GALT and PBMCs was observed, suggesting a novel role for the GALT in maintenance of the viral reservoirs [74]. It has been demonstrated through mathematical modelling that the unique sequences of HIV predominant plasma clones, which are not found in the reservoir could act as labels for the kinetics of cell entry into the viral reservoir [98]. It was calculated that $0-70$ cells are able to enter the reservoir per day in HAART treated patients, which is considerably lower than the total viral reservoir. It was concluded that viral replication cannot replenish the reservoir and therefore cannot contribute to the stability of the reservoir [116]. The influx of cells was shown to represent less than $0.0001 \%$ of the total viral reservoir [47], which suggests that the reservoir cannot be replenished by replicating virus [19].

\subsection{HAART intensification studies}

Poor HAART drug potency or pharmacodynamics could lead to suboptimal drug penetration into 'sanctuary sites' and could be responsible for the viral replication observed in the above studies [117]. Tissues bordering blood-tissue barriers, secondary to cell tight junctions were theorised to be unpermissive to drug penetration [10], and thus act as drug sanctuary sites for continued viral replication. Tissues such as the central nervous system, retina [118] and testes [119] could represent such sites. The latter study discovered replication competent HIV in the seminal cells of some men on HAART and it was found that penetration of the HIV protease inhibitor into the male genital tract was poor [120]. However, in another study, the HIV-RNA levels in semen [121] and in the cervico-vaginal fluids [122] of HIV-infected patients were shown to fall to below detectable levels on HAART. However, studies have shown a decrease in tissue and CSF viremia induced by HAART, in parallel with that seen in plasma, suggesting that antiretroviral drugs do penetrate these sanctuary sites, but possibly at suboptimal concentrations [43]. However, drug penetration to sites such as the gut, CNS and brain have yet to be fully elucidated. It could be that residual viremia is expressed sporadically from the latent reservoirs and also replicates, possibly in drug sanctuary sites and in other viral reservoirs, suggesting the possibility that both sporadic release of virus from latent reservoirs and de novo infection and viral replication might be occurring together [123].

HAART intensification regimes were devised to see if a greater effect on inhibition of viral production could be demonstrated. However, the intensification of antiretroviral drugs therapy in nine HIV-1 infected individuals on successful ART therapy showed no change in persistent virus levels as measured by the single copy assay [99].

Raltegravir is a potent HIV integrase inhibitor, and since integrated proviral DNA is present in infected T-cells, the inclusion of Raltegravir into HAART regimens was hypothesised to impact on latency [61, 124]. However, short-course (28 day) Raltegravir intensification studies on 10 subjects already receiving HAART, with long term suppression, was shown not to reduce their persistent viremia, compared to pre-intensification levels [125]. A recent 
randomised controlled and double-blinded clinical trial investigating the effect of 12 weeks of Raltegravir intensification on low-level residual viremia in HIV-infected patients did not demonstrate a reduction in plasma HIV-1 levels [126]. On another Raltegravir intensification regime, a transient, but specific increase in episomal cDNA was seen in $30 \%$ of the HAART suppressed subjects tested, especially in those that received a protease inhibitor intensification regime. In subjects with high levels of episomal cDNA, the immune activation was higher than baseline levels, and normalised after drug intensification. This may be evidence that viral replication continues, although changes in plasma viremia were not observed [127].

The HIV-RNA levels in plasma, PBMC, duodenal, ileal, colonic and rectal biopsies from seven patients on intensified raltegravir-containing HAART regimes, revealed evidence for residual HIV replication in the ileum, where a decrease in unspliced HIV levels and increase in CD4+ T-cells was discovered, although it is unknown whether this local virus contributes to plasma viremia [71]. Although subsets of patients have ongoing viral replication during therapy, this does not seem to impact on viral plasma RNA levels [127] and it is thus apparent that eradication of HIV through intensification regimes with existing antiretroviral drugs is unlikely [128].

\subsection{Viral rebound and its origin}

When HAART is discontinued, most patients, even those who suppress viral load to below detectable levels, will experience rapid viral rebound (mean time 9-17 days) [27] [129] and high plasma HIV levels. However, if HAART treatment is initiated early, some patients are able to suppress virus rebound for extended periods of time after scheduled treatment interruptions (STI), although this is rare [24]. In another recent study, eight patients out of 45 had undetectable plasma viraemia and in these, those that started HAART early had a significantly lower amount of latently infected cells. Also, one patient who had undetectable plasma and tissue HIV levels the virus rebounded 50 days after STI, suggesting early HAART treatment may help reduce the latent reservoir in a select few [130]. As well as in patients, this has also been observed in acutely SIV-infected macaques, where early treatment correlated with a more active SIV-specific immune response on commencement of STIs [131]. The rebounding virus could potentially be an early viral clone, whose virus-specific $\mathrm{T}$ cell was killed during the acute phase of HIV infection [132], an escape mutant that is unrecognised by pre-existing antibodies or cytotoxic CD8+ T cells (CTLs) [133] or from HIV-specific B and T cells, 'exhausted' from chronic antigen exposure [1].

In a study by Zhang et al, the rebounding virus, after HAART discontinuation in five aviremic patients was identical to that found in the latent viral reservoir. However, in three patients who showed some residual viral replication, the rebounded virus was genetically distinct to that found in the latent reservoir, but related to viral variants isolated in the lymphoid tissues [134]. No genetic variation was seen in HIV Env C2-V3-C2 regions during HAART suppression, when the viral diversity between pre-treatment and scheduled twoweek structured treatment interruptions was examined longitudinally in 20 chronically HIV-infected patients [135]. The rebounding virus was shown to be homogenous, suggesting a clonal origin post-reactivation. Also, expansion of distinct clonal HIV lineages during STIs was seen, suggesting stochastic reactivation of different clones from latently infected cells. Diversity increased slowly after treatment was stopped, although 2.5 years 
elapsed before the viral diversity reached the same levels as found in pre-treatment samples [135]. However, in order to study rebounded virus, there are ethical issues.

Other studies show that any rebound virus observed after STIs does not originate from PBMC or the lymph system, although this may be due to sampling error. Chun et al showed, using tracking and heteroduplex mobility assays that latent HIV present in resting CD4+ T-cells was genetically distinct to the rebounding virus seen in the majority of patients with discontinued HAART treatment and it was suggested that other persistent HIV reservoirs could be responsible for viral rebound after HAART cessation [136]. In another study, envelope gene sequence homology was identified in 12 patients, who received regular cycling scheduled HAART interruptions, at various time points. HIV populations in three quarters of patients diverged between STI cycles, hinting that multiple compartments could contribute to rebounding virus diversity [137]. Through the phylogenetic analysis of HIV polymerase during STI studies, it was discovered that rebounding HIV variants were not related directly to their temporal ancestor, but formed a separate population cluster, which indicates re-emergence of a latent viral population [138]. Also, the genetic diversity, as discovered by tracking and heteroduplex assays, of HIV in lymph node B and CD4+ Tcells were similar, but more distantly related to peripheral blood-derived B and CD4+ T cells in chronically infected patients, suggesting B and T cell 'cross-talk' in lymph nodes [139].

A recent longitudinal study has revealed the gut mucosal viral reservoir not to represent the major viral sequences obtained in plasma, post STI, although it was shown to be an early and stable reservoir in the three patients studied pre and post HAART interruption. Rebound viremia varients also did not replenish the GALT HIV-reservoir. Also, inflammatory responses and a severe loss in gut mucosal CD4+ T-cells were observed on STI induction at the gut mucosa [140].

In six patients whose HIV viremia was controlled for at least 20 months, the episomal and proviral HIV-DNA pre-STI were analysed phylogenetically and compared to rebound virus sequences isolated during a STI study [141]. It appeared, in this study, that the rebounded sequences clustered with envelope regions of pre-rebound episomal DNA, and since episomes are evidence of recent HIV-infection, they may represent a reservoir that contributes to viral rebound after the cessation of HAART and that can lead to treatment failure [141]. This supports the idea that low level viral replication on HAART contributes to viral rebound, as in another study the rebounded sequences of HIV quasispecies closely resembled the sequences observed in replicating virus, before STI [142].

In a further study, HAART-treated patients with undetectable viremia were treated with Didanosine and Hydroxyurea, followed by low dose OKT-3 and IL-2 therapy for 2 weeks, after which treatment was discontinued. 6 months after viral rebound, a shift towards dual tropism in semen cell-associated, but not plasma HIV-1 proviral DNA was detected through the appearance of an $\mathrm{X} 4$ provirus. Also, the virus responsible for plasma rebound was not represented in the semen microenvironment, suggesting that there is viral compartmentalization after an intensification and stimulatory HIV-1 eradication protocol [80] [143].

\section{Approaches to HIV eradication}

Approaches to HIV eradication have focused on the induction of T-cell activation, induction of viral expression with and without activation of the host cell, and a selection of other novel therapeutic strategies [3]. It should be noted that HIV has been 'eradicated' in one HIV- 
infected patient who was also diagnosed with acute myeloid leukemia resulting in a CCR5 delta32 stem cell transplant. CCR5 is a key co-receptor that HIV uses for cellular entry, and homozygosity for a $32 \mathrm{bp}$ deletion in the CCR5 gene results in resistance to HIV-1 infection. This patient remains free from viral rebound 20 months after the stem cell transplant and in the absence of HAART [144].

\subsection{Induction of T-cell activation}

The theory behind this therapeutic strategy is that activation of resting CD4+ T-cells could induce HIV LTR transcription and hence viral expression, thus clearing virus from latently infected cells [3]. Immune activation therapy, involving agents such as IL-2 and OKT3 (an anti T-cell receptor antibody) could activate T-cell receptors (TCRs) and through multiple signalling pathways could induce histone acetylation of the integrated HIV-DNA site, thus stimulating viral transcription and viral eradication from the latently infected cell. IL-2 therapy was shown to temporarily induce HIV transcription in 4/10 patients and CD4+ Tcell expansion to levels 50\% higher than at baseline [145] and $94.8 \%$ higher than baseline after 6 months on high level IL-2 doses [146]. Through CD4+ T-cell labelling, naïve and TCM cells were preferentially expanded and had a more prolonged survival time [147]. IL-2 treatment also induced prolonged CD4+ T-cell survival, in combination with the antiretroviral drugs, Zidovudine and Didanosine, and viremia remained undetectable [148]. The amount of latently infected cells in patients receiving IL-2 therapy in combination with HAART drug regimens was shown to decrease, relative to patients receiving HAART alone [149]. However, in patients who received HAART and IL-2 within 6 months of primary HIV infection, no decrease in the amount of latently infected cells was seen compared to HAART-only treated patients [150]. In other studies, early HAART treatment was able to restore CD4+ T-cells to near normal levels, although virus rebounded rapidly after the treatment was interrupted [151-152]. Also, IL-2 therapy in two HIV-infected patients was shown to induce a population of T-cells that expressed the transcription factor, FOXP3 [153], and it has shown elsewhere that FOXP3 can repress HIV expression [154].

In studies attempting viral 'purging' where HIV infected patients were treated with IL-2, HAART and OKT-3 to deplete T cells, cytokine storms were induced and severe toxicities resulted [155], with the added issue that CD4+ cell levels were shown to never fully recover in a separate study after OKT3 treatment [156]. If OKT-3 is used at lower concentrations, it was discovered that rebounded virus genotypes were vastly different to those isolated before treatment, indicating the drug regime had altered the viral pool but not eradicated the virus [151]. In another study, commencement of Didanosine and Hydroxyurea treatment on HAART-treated patients who maintained viral RNA levels below 50 copies $/ \mathrm{ml}$ for a month, followed by low dose OKT-3 therapy with IL-2 did not stop rebound viremia after STIs [143]. Intensification studies with hydroxyurea, didanosine and low-dose OKT3 also did not to fully ablate HIV-1 reservoirs in vivo [151].

\subsection{Induction of viral expression}

During HIV infection, plasma levels of IL-7, a cytokine necessary for T cell homeostasis, increase as CD4+ T-cell counts fall [157], and once CD4+ T-cell levels start to increase on HAART, levels of IL-7 have been shown to decline [158]. IL-7 was shown using the SCIDhu mouse model to stimulate the expression of latent HIV from primary human T cells and thymocytes, with little effect on the cell phenotype, highlighting IL-7 as a possible therapeutic agent [159]. Studies have shown that IL-7 can induce latent virus expression ex 
vivo from CD4+ T-cells from patients who are receiving HAART, although to differing extents. For example, there was no statistically significant difference in viral re-expression between Il-7 and mitogen-treated latently infected CD4 cells, although IL-7 itself could induce viral recovery [160]. It was also found that IL-7 could induce the expression of unique viral isolates through activation of the JAK/STAT pathway, and could thus be of clinical significance [161]. However, IL-7 has also been shown to promote proliferation of latently HIV-infected cells, thus causing doubt as to whether it is clinically useful [52].

HIV proviral expression from HAART-treated patient cell lines and primary cells can also be induced without cellular proliferation through PKC and NF-kB signalling, mediated by prostratin, a phorbol ester isolated from the Samoan medicinal plant 'Homolanthus nutans' [162-163]. The usefulness of prostratin as a drug was restricted because of its limited supply, however synthesis of prostratin has recently been developed synthetically [164]. In cell lines, prostratin can stimulate HIV transcription through NF-kB activation, mediated by PKC [165]. Prostratin has also been shown in other studies to reactivate latent HIV from primary blood lymphocytes and lymphoid tissue and inhibit infection of HIV by down-regulating the expression of the co-receptors CXCR4 and CD4, thus increasing the chance of HIV purging without the risk of new rounds of HIV infection [166-167]. Prostratin, alone, has been shown to reactivate latent HIV from thymocytes and primary human peripheral blood lymphocytes in the SCID-hu (Thy/Liv) model, in the absence of cellular proliferation [168]. Recently, the PKC activator, bryostatin-1, which has well documented pharmacokinetic and toxicity profiles, has been shown to reactivate HIV-1 from Jurkat-LAT-GFP cells through a PKC mediated mechanism and to synergise with other HDAC inhibitors such as VPA. Byrostatin-1 downregulates CD4 and CXCR4 and was thus able to prevent de novo HIV infection [192].

Hexamethylene bisacetamide (HMBA) can also induce the expression of the HIV-LTR, through the modulation of PKC, in rat and human fibroblasts [169] by modulating the PI3-K signalling cascade [170]. It downregulates CD4 expression, thus preventing new rounds of de novo infection and propagation in PBMC cell cultures [171] and is well tolerated in phase II clinical trials, despite being tested as a potential anti-cancer drug [172]. Unlike Prostratin which operates via Tat, an HIV protein that enhances the RNAP II elongation step of the viral DNA template, HMBA activates proviral transcription in the absence of Tat [173], and high-level viral reactivation is Tat dependant [174]. High levels of Tat can out-compete HEXIM and recruit pTEFb to the HIV promoter [175]. HMBA can induce liberation of pTEFb from the inhibitor HEXIM in the absence of Tat, so pTEFb can bind to the HIV LTR and induce processive viral transcription from abortive transcription [176].

\subsection{Induction of viral expression without host cell activation}

The problem with inducing cellular activation as well as viral reactivation from latency is the increase in de novo activated CD4+ T-cells - the targets for HIV infection [3]. This global T-cell activation could result in an increase the number of cells susceptible to HIV infection at a level that HAART may not be able to contain [149], thereby enhancing rather than reducing the reservoir. Approaches, therefore, need to be developed which result in viral transcription without widespread $\mathrm{T}$ cell activation.

Pyrrole imidazole polyamides are small molecule drugs that can recognise specific HIV sequences [177] and targeting of these small molecules to sequences in the HIV promoter has been shown to block histone deacetylase (HDAC) recruitment, resulting in increased HIV-LTR expression [178]. Viable virus was recovered from pyrrole imidazole polyamide- 
treated cell cultures of resting CD4+ T-cells, that were originally isolated from aviremic patients on HAART [179].

HDAC inhibitors have also been shown to release integrated HIV from latency in the HIV reservoir [180]. TNF-a was found to cause a disruption in chromatin packaging of the HIV-1 promoter region, specifically at nucleosome-1 (nuc-1), suggesting that chromatin plays an important role in the repression of HIV transcription and thus, induction of latency [181]. Trichostatin A, a HDAC inhibitor, was shown to induce acetylation of histone proteins, also at nuc-1, independent of NF-kB and caused transcriptional activation of the HIV-1 promoter in a dose dependant manner [182]. Also, TSA was shown to synergise with TNF-a to cause NF-kB mediated re-expression of the HIV-LTR [183].

Valproic acid (VPA), also an HDAC inhibitor, has been shown to increase HIV gene expression and virus production in cultured latently infected cells [184-185]. VPA was shown in another study to induce the expression of HIV from resting CD4+ T-cells, isolated from patients receiving HAART treatment without fully activating the cells or enhancing new rounds of HIV infection [186]. An accelerated and significant decline in the number of replication competent virions in resting CD4+ T-cells was observed in three out of four patients who received a combination of intensified HAART (enfurvitide) and an HDAC inhibitor (VPA) [187]. However, VPA itself, without ART intensification, was found not to be sufficient for a reduction in HIV infection of CD4+ T-cells from the majority $(7 / 11)$ HAART treated patients, although in the absence of low level viremia, there was an associated reduction in T-cell infection [188]. The infection rates of resting CD4+ T-cells from patients on standard HAART and from patients receiving HAART in combination with VPA, prescribed for neurological or mood disorders, were not sufficiently different [189] and in a study of seven patients who had 5.1 months of drug treatment, no change in CD4+ T-cell levels were observed. On comparison of total cellular HIV DNA and HIV RNA isolated from resting CD4+ T-cells from 10 patients on HAART alone and 10 patients receiving ART in combination with VPA for seizure treatment, no difference in levels of total and integrated HIV DNA or HIV RNA was observed [190]. HAART treatment intensification with VPA in chronic HIV disease also did not significantly reduce levels of resting T-cell infection or impact plasma viral load [191].

Suberoylanilide hydroxamic acid (SAHA), also known as Vorinostat, is a selective class I HDAC inhibitor and has been shown to induce HIV outgrowth from infected J89 Jurkat T cell lines. SAHA also induced HIV production from cells from ART-treated chronically HIV-infected patients, including from memory T-cells and PBMCs [193-194]. Preclinical and clinical trials have shown that the drug is well tolerated and shows little major toxicity at effective concentrations [195].

Oxamflatin, belongs to a novel hydroxamate class of HDAC inhibitor drugs, and has FDA approval in the treatment of solid tumours and haematological malignancies. In the latently infected ACH2 and Jurkat cell lines, it has a EC50 of 3.5uM/L [196] and can induce HIV-1 transcription through the modulation of histone $\mathrm{H} 3$ and $\mathrm{H} 4$ acetylation in latently infected cells [197]. Another novel HDAC NCH-51 was shown to activate latent HIV-1 gene expression with minimal cytotoxicity, through SP1 sites [198].

The 5'LTR of HIV is CpG hypermethylated. The DNA methylation inhibitor 5-aza-2'deoxycytidine (aza-CdR) when combined with HDACs, PKC agonists or TNF-a may cause HIV reactivation, especially in combination with SAHA [199]. Aza-CdR was shown to reactivate HIV-1 from latency through inhibition of MBD2 and HDAC2 recruitment to 
methylated CpG islands. The drug could also potently synergise with the NF-kB activators, prostratin or TNF-a [200].

Screening studies have been performed to isolate potent small molecule drugs that can reactivate HIV from primary human CD4+ T-cells, transfected with BCL2 to increase cell survival. It was discovered in this study that 5HN (5-hydroxynaphthalene-1,4-dione), a natural quinone found in the bark and roots of the black walnut tree, could reactivate latent HIV-1 in a similar manner to anti-CD3 and anti-CD28 antibody combinations, without inducing global T-cell activation [201].

\subsection{Combination therapy}

Ex vivo studies have shown that a combination of prostratin with VPA or SAHA was more efficient at reactivating latently infected CD8+ T-cell-depleted PBMCs from HAART-treated patients, who had plasma RNA levels below 50 copies/ml [202]. In one study, a synergistic relationship in reactivating latent HIV from PBMCs between SAHA and prostratin was observed, and it was discovered that this combination of drugs could target a wide range of latently integrated sites, irrespective of some viral variants and subtypes [203]. Also, the novel hydroxamate class HDAC inhibitor Oxamflatin has demonstrated synergistic effects with TNF-a, prostratin and aza-cdr [197].

\subsection{Novel, and new therapies used for eradication studies}

The immunotoxin 3B3(Fv)-PE38, a recombinant derivative of Pseudomonas aeruginosa exotoxin A and gp120 targeting moieties can selectively kill HIV-1 infected cells in vitro, and potently inhibits the spread of viral infection in primary human macrophages, with little or no toxicity in non-human primates [204]. If CD4+ memory T cells are destroyed, then the reservoir of latent HIV would be removed. This theory led to the development of the antiCD45RO ricin immunotoxin. An ex vivo study with latently infected CD4+ T-cells from patients with undetectable plasma viral loads showed a specific CD4+ memory cell decrease with little decrease in CD8+ memory T cells. However this therapy would not be able to discriminate between infected and uninfected memory T-cells and would severely compromise broader immunological memory [205].

The P-glycoprotein, expressed in cell membranes, can pump antiretroviral drugs, such as HIV protease inhibitors, out of the cell, reducing drug concentrations to sub-therapeutic levels [206]. A possible solution to this could be biodegradable Tat peptide-conjugated nanoparticles. These can be loaded with anti-HIV drugs and can enhance drug transport across the blood brain barrier, resulting in increased bioavailability of drugs to the CNS, a known reservoir for HIV [207]. Nanoparticles with special optical properties called quantum rods (QRs), conjugated to the antiretroviral drug Saquinavir and the Transferrin receptor (to mediate its transport across the blood-brain barrier), decreased HIV p24 production by $63 \%$ and the HIV-1 LTR gene expression by $93 \%$ in infected monocytes [208].

Various anticancer drugs such as 5-azacytidine (5-AZC), 5-fluorouracil, (5-FU), methotrexate, cytoine arabinoside and vinblastine, as well as phorbol myristate acetate (PMA) and phytohemagglutinin (PHA) could induce the expression of HIV-1 from a latently infected ACH2 cell line [209]. Based on previous observations, where IVIG treatment for patients with Guillain Barre syndrome led to an increase in plasma HIV RNA levels in patients who were HIV positive, IVIG therapy has recently been shown to reduce the latent viral reservoir levels in half of the HAART-treated patients studied [210]. 


\section{Concluding remarks}

Despite the success of HAART in controlling HIV viraemia, it is clear that current drug strategies will not eradicate HIV from an infected individual and thus cure the disease. In fact, more people contract HIV daily, than initiate HAART [211]. The main barrier to viral eradication lies with the persistent and sporadic release of virus from long term viral reservoirs, such as the latently infected resting CD4+ T-cell population, or from residual virus replication in drug sanctuary sites due to poor HAART penetration, pharmacokinetics and bioavailability [3]. A sustained background low level viraemia (median of 3.34 copies / $\mathrm{ml}$ ) with an 'infinite half life' in patients on HAART was reported in a 7 year study [94] and was confirmed in a similar 11 year study [95]. It is not known whether these virions represent a replication competent form of virus, however viable virus has been isolated from the plasma of a single HAART treated patient using recombinant clones [96], which may suggest that residual viraemia does contribute to rebounded viremia once therapy is stopped. The source of residual and rebounded virus is not presently known.

The theory that the source of residual viremia seen in patients on HAART represents spontaneous release of virus from the latent cell reservoirs is more likely than there being residual viral replication since drug intensification studies have not shown a reduction in plasma viral load [191], and no evidence for viral evolution has been gleaned in phylogenetic analyses of residual viremia [97-98, 135]. It may be that the amount of intensification needed to completely inhibit viral replication at such low levels has been underestimated. The argument for on-going viral replication on HAART is supported by studies showing transient increases in 2-LTR circles following treatment intensification with Raltegravir [127], and that the episomal sequences may reflect a separate reservoir [141]. It may be more likely that residual viraemia arises from a combination of both processes [123]. Therapies to target the latent viral reservoir have focused around the forced re-expression of virus from latently infected cells, using global T-cell activators such as IL-2, or by using compounds such as IL-7, prostratin or HBMA, that can also induce T cell activation [3]. However the main issue surrounding these drugs is that they also potentially create more potential target cells for HIV infection [3, 149]. Current research is focussed around FDA approved HDAC inhibitors like Valproic Acid and SAHA and their role in forcing viral expression through epigenetic mechanisms at the chromatin level. However VPA has enjoyed limited success in all but one clinical trial [187, 189-191], and the need for the development of more potent HDACs remains a high priority. It is likely that a cocktail of potent anti-latency compounds will be needed in concert with intensified HAART regimes to eradicate HIV. However at the moment, with current knowledge, the eradication of HIV from infected patients remains a formidable challenge.

\section{References}

[1] Trono, D., et al., HIV persistence and the prospect of long-term drug-free remissions for HIV-infected individuals. Science, 2010. 329(5988): p. 174-80.

[2] Piatak, M., Jr., et al., High levels of HIV-1 in plasma during all stages of infection determined by competitive PCR. Science, 1993. 259(5102): p. 1749-54.

[3] Bowman, M.C., N.M. Archin, and D.M. Margolis, Pharmaceutical approaches to eradication of persistent HIV infection. Expert Rev Mol Med, 2009. 11: p. e6. 
[4] Stebbing, J., B. Gazzard, and D.C. Douek, Where does HIV live? N Engl J Med, 2004. 350(18): p. 1872-80.

[5] Douek, D.C., L.J. Picker, and R.A. Koup, T cell dynamics in HIV-1 infection. Annu Rev Immunol, 2003. 21: p. 265-304.

[6] Perelson, A.S., et al., Decay characteristics of HIV-1-infected compartments during combination therapy. Nature, 1997. 387(6629): p. 188-91.

[7] Ho, D.D., et al., Rapid turnover of plasma virions and CD4 lymphocytes in HIV-1 infection. Nature, 1995. 373(6510): p. 123-6.

[8] Wei, X., et al., Viral dynamics in human immunodeficiency virus type 1 infection. Nature, 1995. 373(6510): p. 117-22.

[9] Zhang, Z., et al., Sexual transmission and propagation of SIV and HIV in resting and activated CD4+ T cells. Science, 1999. 286(5443): p. 1353-7.

[10] Pomerantz, R.J., Reservoirs, sanctuaries, and residual disease: the hiding spots of HIV-1. HIV Clin Trials, 2003. 4(2): p. 137-43.

[11] Nickle, D.C., et al., Importance and detection of virus reservoirs and compartments of HIV infection. Curr Opin Microbiol, 2003. 6(4): p. 410-6.

[12] Blankson, J.N., D. Persaud, and R.F. Siliciano, The challenge of viral reservoirs in HIV-1 infection. Annu Rev Med, 2002. 53: p. 557-93.

[13] Finzi, D., et al., Latent infection of CD4+ T cells provides a mechanism for lifelong persistence of HIV-1, even in patients on effective combination therapy. Nat Med, 1999. 5(5): p. 512-7.

[14] Siliciano, J.D., et al., Long-term follow-up studies confirm the stability of the latent reservoir for HIV-1 in resting CD4+ T cells. Nat Med, 2003. 9(6): p. 727-8.

[15] Zhang, L., et al., Quantifying residual HIV-1 replication in patients receiving combination antiretroviral therapy. N Engl J Med, 1999. 340(21): p. 1605-13.

[16] Ramratnam, B., et al., The decay of the latent reservoir of replication-competent HIV-1 is inversely correlated with the extent of residual viral replication during prolonged anti-retroviral therapy. Nat Med, 2000. 6(1): p. 82-5.

[17] Bartlett, J.G., New guidelines for the use of antiretroviral agents in HIV-infected adults and adolescents. Hopkins HIV Rep, 2001. 13(2): p. 1, 15.

[18] Hammer, S.M., et al., Treatment for adult HIV infection: 2006 recommendations of the International AIDS Society--USA panel. Top HIV Med, 2006. 14(3): p. 827-43.

[19] Shen, L. and R.F. Siliciano, Viral reservoirs, residual viremia, and the potential of highly active antiretroviral therapy to eradicate HIV infection. J Allergy Clin Immunol, 2008. 122(1): p. 22-8.

[20] Gulick, R.M., et al., Treatment with indinavir, zidovudine, and lamivudine in adults with human immunodeficiency virus infection and prior antiretroviral therapy. $\mathrm{N}$ Engl J Med, 1997. 337(11): p. 734-9.

[21] Palella, F.J., Jr., et al., Declining morbidity and mortality among patients with advanced human immunodeficiency virus infection. HIV Outpatient Study Investigators. N Engl J Med, 1998. 338(13): p. 853-60.

[22] Maldarelli, F., et al., ART suppresses plasma HIV-1 RNA to a stable set point predicted by pretherapy viremia. PLoS Pathog, 2007. 3(4): p. e46.

[23] Chun, T.W., et al., Early establishment of a pool of latently infected, resting CD4(+) T cells during primary HIV-1 infection. Proc Natl Acad Sci U S A, 1998. 95(15): p. 8869-73. 
[24] Hocqueloux, L., et al., Long-term immunovirologic control following antiretroviral therapy interruption in patients treated at the time of primary HIV-1 infection. AIDS, 2010. 24(10): p. 1598-601.

[25] Haase, A.T., Targeting early infection to prevent HIV-1 mucosal transmission. Nature, 2010. 464(7286): p. 217-23.

[26] Chun, T.W., et al., Presence of an inducible HIV-1 latent reservoir during highly active antiretroviral therapy. Proc Natl Acad Sci U S A, 1997. 94(24): p. 13193-7.

[27] Harrigan, P.R., M. Whaley, and J.S. Montaner, Rate of HIV-1 RNA rebound upon stopping antiretroviral therapy. AIDS, 1999. 13(8): p. F59-62.

[28] Lohse, N., et al., Survival of persons with and without HIV infection in Denmark, 19952005. Ann Intern Med, 2007. 146(2): p. 87-95.

[29] Fantoni, M., C. Del Borgo, and C. Autore, Evaluation and management of metabolic and coagulative disorders in HIV-infected patients receiving highly active antiretroviral therapy. AIDS, 2003. 17 Suppl 1: p. S162-9.

[30] Barbaro, G., Metabolic and cardiovascular complications of highly active antiretroviral therapy for HIV infection. Curr HIV Res, 2006. 4(1): p. 79-85.

[31] Volberding, P.A. and S.G. Deeks, Antiretroviral therapy and management of HIV infection. Lancet, 2010. 376(9734): p. 49-62.

[32] Hecht, R., et al., Critical choices in financing the response to the global HIV/AIDS pandemic. Health Aff (Millwood), 2009. 28(6): p. 1591-605.

[33] McDougal, J.S., et al., Cellular tropism of the human retrovirus HTLV-III/LAV. I. Role of T cell activation and expression of the T4 antigen. J Immunol, 1985. 135(5): p. 3151-62.

[34] Korin, Y.D. and J.A. Zack, Nonproductive human immunodeficiency virus type 1 infection in nucleoside-treated G0 lymphocytes. J Virol, 1999. 73(8): p. 6526-32.

[35] Bukrinsky, M.I., et al., Active nuclear import of human immunodeficiency virus type 1 preintegration complexes. Proc Natl Acad Sci U S A, 1992. 89(14): p. 6580-4.

[36] Zack, J.A., et al., HIV-1 entry into quiescent primary lymphocytes: molecular analysis reveals a labile, latent viral structure. Cell, 1990. 61(2): p. 213-22.

[37] Zack, J.A., et al., Incompletely reverse-transcribed human immunodeficiency virus type 1 genomes in quiescent cells can function as intermediates in the retroviral life cycle. J Virol, 1992. 66(3): p. 1717-25.

[38] Pierson, T.C., et al., Molecular characterization of preintegration latency in human immunodeficiency virus type 1 infection. J Virol, 2002. 76(17): p. 8518-31.

[39] Lassen, K., et al., The multifactorial nature of HIV-1 latency. Trends Mol Med, 2004. 10(11): p. 525-31.

[40] Marcello, A., Latency: the hidden HIV-1 challenge. Retrovirology, 2006. 3: p. 7.

[41] Chun, T.W., et al., In vivo fate of HIV-1-infected T cells: quantitative analysis of the transition to stable latency. Nat Med, 1995. 1(12): p. 1284-90.

[42] Brady, T., et al., HIV integration site distributions in resting and activated CD4+ T cells infected in culture. AIDS, 2009. 23(12): p. 1461-71.

[43] Cavert, W., et al., Kinetics of response in lymphoid tissues to antiretroviral therapy of HIV-1 infection. Science, 1997. 276(5314): p. 960-4.

[44] Perelson, A.S., et al., HIV-1 dynamics in vivo: virion clearance rate, infected cell lifespan, and viral generation time. Science, 1996. 271(5255): p. 1582-6. 
[45] Blankson, J.N., et al., Biphasic decay of latently infected CD4+ T cells in acute human immunodeficiency virus type 1 infection. J Infect Dis, 2000. 182(6): p. 1636-42.

[46] Finzi, D., et al., Identification of a reservoir for HIV-1 in patients on highly active antiretroviral therapy. Science, 1997. 278(5341): p. 1295-300.

[47] Chun, T.W., et al., Quantification of latent tissue reservoirs and total body viral load in HIV-1 infection. Nature, 1997. 387(6629): p. 183-8.

[48] Wong, J.K., et al., Recovery of replication-competent HIV despite prolonged suppression of plasma viremia. Science, 1997. 278(5341): p. 1291-5.

[49] Chun, T.W., et al., Induction of HIV-1 replication in latently infected CD4+ T cells using a combination of cytokines. J Exp Med, 1998. 188(1): p. 83-91.

[50] Pierson, T., et al., Characterization of chemokine receptor utilization of viruses in the latent reservoir for human immunodeficiency virus type 1. J Virol, 2000. 74(17): p. 7824-33.

[51] Brooks, D.G., et al., Generation of HIV latency during thymopoiesis. Nat Med, 2001. 7(4): p. 459-64.

[52] Chomont, N., et al., HIV reservoir size and persistence are driven by T cell survival and homeostatic proliferation. Nat Med, 2009. 15(8): p. 893-900.

[53] Sonza, S., et al., Monocytes harbour replication-competent, non-latent HIV-1 in patients on highly active antiretroviral therapy. AIDS, 2001. 15(1): p. 17-22.

[54] Gartner, S., et al., The role of mononuclear phagocytes in HTLV-III/LAV infection. Science, 1986. 233(4760): p. 215-9.

[55] Ho, D.D., T.R. Rota, and M.S. Hirsch, Infection of monocyte/macrophages by human T lymphotropic virus type III. J Clin Invest, 1986. 77(5): p. 1712-5.

[56] Mavigner, M., et al., HIV-1 residual viremia correlates with persistent T-cell activation in poor immunological responders to combination antiretroviral therapy. PLoS One, 2009. 4(10): p. e7658.

[57] Zhu, T., HIV-1 in peripheral blood monocytes: an underrated viral source. J Antimicrob Chemother, 2002. 50(3): p. 309-11.

[58] Pelchen-Matthews, A., B. Kramer, and M. Marsh, Infectious HIV-1 assembles in late endosomes in primary macrophages. J Cell Biol, 2003. 162(3): p. 443-55.

[59] Sharova, N., et al., Macrophages archive HIV-1 virions for dissemination in trans. EMBO J, 2005. 24(13): p. 2481-9.

[60] Markowitz, M., et al., Rapid and durable antiretroviral effect of the HIV-1 Integrase inhibitor raltegravir as part of combination therapy in treatment-naive patients with HIV-1 infection: results of a 48-week controlled study. J Acquir Immune Defic Syndr, 2007. 46(2): p. 125-33.

[61] Murray, J.M., et al., Antiretroviral therapy with the integrase inhibitor raltegravir alters decay kinetics of HIV, significantly reducing the second phase. AIDS, 2007. 21(17): p. $2315-21$.

[62] Chun, T.W. and A.S. Fauci, Latent reservoirs of HIV: obstacles to the eradication of virus. Proc Natl Acad Sci U S A, 1999. 96(20): p. 10958-61.

[63] Heath, S.L., et al., Follicular dendritic cells and human immunodeficiency virus infectivity. Nature, 1995. 377(6551): p. 740-4.

[64] Geijtenbeek, T.B., et al., Identification of DC-SIGN, a novel dendritic cell-specific ICAM3 receptor that supports primary immune responses. Cell, 2000. 100(5): p. 575-85. 
[65] Hlavacek, W.S., et al., Influence of follicular dendritic cells on decay of HIV during antiretroviral therapy. Proc Natl Acad Sci U S A, 2000. 97(20): p. 10966-71.

[66] Hlavacek, W.S., C. Wofsy, and A.S. Perelson, Dissociation of HIV-1 from follicular dendritic cells during HAART: mathematical analysis. Proc Natl Acad Sci U S A, 1999. 96(26): p. 14681-6.

[67] Hlavacek, W.S., et al., Retention of antigen on follicular dendritic cells and B lymphocytes through complement-mediated multivalent ligand-receptor interactions: theory and application to HIV treatment. Math Biosci, 2002. 176(2): p. 185-202.

[68] Keele, B.F., et al., Characterization of the follicular dendritic cell reservoir of human immunodeficiency virus type 1. J Virol, 2008. 82(11): p. 5548-61.

[69] Moris, A., et al., DC-SIGN promotes exogenous MHC-I-restricted HIV-1 antigen presentation. Blood, 2004. 103(7): p. 2648-54.

[70] Yukl, S.A., et al., Differences in HIV burden and immune activation within the gut of HIV-positive patients receiving suppressive antiretroviral therapy. J Infect Dis, 2010. 202(10): p. 1553-61.

[71] Yukl, S.A., et al., Effect of raltegravir-containing intensification on HIV burden and Tcell activation in multiple gut sites of HIV-positive adults on suppressive antiretroviral therapy. AIDS, 2010. 24(16): p. 2451-60.

[72] Mowat, A.M. and J.L. Viney, The anatomical basis of intestinal immunity. Immunol Rev, 1997. 156: p. 145-66.

[73] Veazey, R.S., et al., Gastrointestinal tract as a major site of CD4+ T cell depletion and viral replication in SIV infection. Science, 1998. 280(5362): p. 427-31.

[74] Chun, T.W., et al., Persistence of HIV in gut-associated lymphoid tissue despite longterm antiretroviral therapy. J Infect Dis, 2008. 197(5): p. 714-20.

[75] Schacker, T., et al., Rapid accumulation of human immunodeficiency virus (HIV) in lymphatic tissue reservoirs during acute and early HIV infection: implications for timing of antiretroviral therapy. J Infect Dis, 2000. 181(1): p. 354-7.

[76] Carter, C.C., et al., HIV-1 infects multipotent progenitor cells causing cell death and establishing latent cellular reservoirs. Nat Med, 2010. 16(4): p. 446-51.

[77] Sundstrom, J.B., et al., Human tissue mast cells are an inducible reservoir of persistent HIV infection. Blood, 2007. 109(12): p. 5293-300.

[78] Zhu, T., et al., Genetic characterization of human immunodeficiency virus type 1 in blood and genital secretions: evidence for viral compartmentalization and selection during sexual transmission. J Virol, 1996. 70(5): p. 3098-107.

[79] Craigo, J.K., et al., Persistent HIV type 1 infection in semen and blood compartments in patients after long-term potent antiretroviral therapy. AIDS Res Hum Retroviruses, 2004. 20(11): p. 1196-209.

[80] Nunnari, G., et al., Residual HIV-1 disease in seminal cells of HIV-1-infected men on suppressive HAART: latency without on-going cellular infections. AIDS, 2002. 16(1): p. 39-45.

[81] Cheng-Mayer, C., et al., Isolates of human immunodeficiency virus type 1 from the brain may constitute a special group of the AIDS virus. Proc Natl Acad Sci U S A, 1989. 86(21): p. 8575-9. 
[82] Kramer-Hammerle, S., et al., Cells of the central nervous system as targets and reservoirs of the human immunodeficiency virus. Virus Res, 2005. 111(2): p. 194213.

[83] Lambotte, O., et al., Persistence of replication-competent HIV in the central nervous system despite long-term effective highly active antiretroviral therapy. AIDS, 2005. 19(2): p. 217-8.

[84] Bell, J.E., An update on the neuropathology of HIV in the HAART era. Histopathology, 2004. 45(6): p. 549-59.

[85] Bruggeman, L.A., et al., Renal epithelium is a previously unrecognized site of HIV-1 infection. J Am Soc Nephrol, 2000. 11(11): p. 2079-87.

[86] Marras, D., et al., Replication and compartmentalization of HIV-1 in kidney epithelium of patients with HIV-associated nephropathy. Nat Med, 2002. 8(5): p. 522-6.

[87] Winston, J.A., et al., Nephropathy and establishment of a renal reservoir of HIV type 1 during primary infection. N Engl J Med, 2001. 344(26): p. 1979-84.

[88] Finzi, D. and R.F. Siliciano, Viral dynamics in HIV-1 infection. Cell, 1998. 93(5): p. 665-71.

[89] Muller, V., J.F. Vigueras-Gomez, and S. Bonhoeffer, Decelerating decay of latently infected cells during prolonged therapy for human immunodeficiency virus type 1 infection. J Virol, 2002. 76(17): p. 8963-5.

[90] Strain, M.C., et al., Heterogeneous clearance rates of long-lived lymphocytes infected with HIV: intrinsic stability predicts lifelong persistence. Proc Natl Acad Sci U S A, 2003. 100(8): p. 4819-24.

[91] Palmer, S., et al., New real-time reverse transcriptase-initiated PCR assay with singlecopy sensitivity for human immunodeficiency virus type 1 RNA in plasma. J Clin Microbiol, 2003. 41(10): p. 4531-6.

[92] Dornadula, G., et al., Residual HIV-1 RNA in blood plasma of patients taking suppressive highly active antiretroviral therapy. JAMA, 1999. 282(17): p. 1627-32.

[93] Di Mascio, M., et al., In a subset of subjects on highly active antiretroviral therapy, human immunodeficiency virus type 1 RNA in plasma decays from 50 to $<5$ copies per milliliter, with a half-life of 6 months. J Virol, 2003. 77(3): p. 2271-5.

[94] Palmer, S., et al., Low-level viremia persists for at least 7 years in patients on suppressive antiretroviral therapy. Proc Natl Acad Sci U S A, 2008. 105(10): p. 387984 .

[95] Hatano, H., et al., Evidence of persistent low-level viremia in long-term HAARTsuppressed, HIV-infected individuals. AIDS, 2010. 24(16): p. 2535-9.

[96] Sahu, G.K., et al., Low-level plasma HIVs in patients on prolonged suppressive highly active antiretroviral therapy are produced mostly by cells other than CD4 T-cells. J Med Virol, 2009. 81(1): p. 9-15.

[97] Brennan, T.P., et al., Analysis of human immunodeficiency virus type 1 viremia and provirus in resting CD4 $+\mathrm{T}$ cells reveals a novel source of residual viremia in patients on antiretroviral therapy. J Virol, 2009. 83(17): p. 8470-81.

[98] Bailey, J.R., et al., Residual human immunodeficiency virus type 1 viremia in some patients on antiretroviral therapy is dominated by a small number of invariant clones rarely found in circulating CD4+ T cells. J Virol, 2006. 80(13): p. 6441-57. 
[99] Dinoso, J.B., et al., Treatment intensification does not reduce residual HIV-1 viremia in patients on highly active antiretroviral therapy. Proc Natl Acad Sci U S A, 2009. 106(23): p. 9403-8.

[100] Hermankova, M., et al., HIV-1 drug resistance profiles in children and adults with viral load of $<50$ copies $/ \mathrm{ml}$ receiving combination therapy. JAMA, 2001. 286(2): p. 196-207.

[101] Persaud, D., et al., Continued production of drug-sensitive human immunodeficiency virus type 1 in children on combination antiretroviral therapy who have undetectable viral loads. J Virol, 2004. 78(2): p. 968-79.

[102] Kieffer, T.L., et al., Genotypic analysis of HIV-1 drug resistance at the limit of detection: virus production without evolution in treated adults with undetectable HIV loads. J Infect Dis, 2004. 189(8): p. 1452-65.

[103] Cohen Stuart, J.W., et al., Transient relapses ("blips") of plasma HIV RNA levels during HAART are associated with drug resistance. J Acquir Immune Defic Syndr, 2001. 28(2): p. 105-13.

[104] Havlir, D.V., et al., Prevalence and predictive value of intermittent viremia with combination hiv therapy. JAMA, 2001. 286(2): p. 171-9.

[105] Nettles, R.E., et al., Intermittent HIV-1 viremia (Blips) and drug resistance in patients receiving HAART. JAMA, 2005. 293(7): p. 817-29.

[106] Neuhaus, J., et al., Markers of inflammation, coagulation, and renal function are elevated in adults with HIV infection. J Infect Dis, 2010. 201(12): p. 1788-95.

[107] Natarajan, V., et al., HIV-1 replication in patients with undetectable plasma virus receiving HAART. Highly active antiretroviral therapy. Lancet, 1999. 353(9147): p. 119-20.

[108] Wong, J.K., et al., Reduction of HIV-1 in blood and lymph nodes following potent antiretroviral therapy and the virologic correlates of treatment failure. Proc Natl Acad Sci U S A, 1997. 94(23): p. 12574-9.

[109] Gunthard, H.F., et al., Evolution of envelope sequences of human immunodeficiency virus type 1 in cellular reservoirs in the setting of potent antiviral therapy. J Virol, 1999. 73(11): p. 9404-12.

[110] Furtado, M.R., et al., Persistence of HIV-1 transcription in peripheral-blood mononuclear cells in patients receiving potent antiretroviral therapy. N Engl J Med, 1999. 340(21): p. 1614-22.

[111] Frenkel, L.M., et al., Multiple viral genetic analyses detect low-level human immunodeficiency virus type 1 replication during effective highly active antiretroviral therapy. J Virol, 2003. 77(10): p. 5721-30.

[112] Sharkey, M.E., et al., Persistence of episomal HIV-1 infection intermediates in patients on highly active anti-retroviral therapy. Nat Med, 2000. 6(1): p. 76-81.

[113] Butler, S.L., E.P. Johnson, and F.D. Bushman, Human immunodeficiency virus cDNA metabolism: notable stability of two-long terminal repeat circles. J Virol, 2002. 76(8): p. 3739-47.

[114] Pierson, T.C., et al., Intrinsic stability of episomal circles formed during human immunodeficiency virus type 1 replication. J Virol, 2002. 76(8): p. 4138-44.

[115] Chun, T.W., et al., HIV-infected individuals receiving effective antiviral therapy for extended periods of time continually replenish their viral reservoir. J Clin Invest, 2005. 115(11): p. 3250-5. 
[116] Sedaghat, A.R., et al., Limits on replenishment of the resting CD4+ T cell reservoir for HIV in patients on HAART. PLoS Pathog, 2007. 3(8): p. e122.

[117] Pierson, T., J. McArthur, and R.F. Siliciano, Reservoirs for HIV-1: mechanisms for viral persistence in the presence of antiviral immune responses and antiretroviral therapy. Annu Rev Immunol, 2000. 18: p. 665-708.

[118] Pomerantz, R.J., et al., Infection of the retina by human immunodeficiency virus type I. N Engl J Med, 1987. 317(26): p. 1643-7.

[119] Zhang, H., et al., Human immunodeficiency virus type 1 in the semen of men receiving highly active antiretroviral therapy. N Engl J Med, 1998. 339(25): p. 1803-9.

[120] Taylor, S., et al., Poor penetration of the male genital tract by HIV-1 protease inhibitors. AIDS, 1999. 13(7): p. 859-60.

[121] Barroso, P.F., et al., Effect of antiretroviral therapy on HIV shedding in semen. Ann Intern Med, 2000. 133(4): p. 280-4.

[122] Cu-Uvin, S., et al., Effect of highly active antiretroviral therapy on cervicovaginal HIV1 RNA. AIDS, 2000. 14(4): p. 415-21.

[123] Tobin, N.H., et al., Evidence that low-level viremias during effective highly active antiretroviral therapy result from two processes: expression of archival virus and replication of virus. J Virol, 2005. 79(15): p. 9625-34.

[124] Stevenson, M., HIV-1 pathogenesis. Nat Med, 2003. 9(7): p. 853-60.

[125] McMahon, D., et al., Short-course raltegravir intensification does not reduce persistent low-level viremia in patients with HIV-1 suppression during receipt of combination antiretroviral therapy. Clin Infect Dis, 2010. 50(6): p. 912-9.

[126] Gandhi, R.T., et al., The effect of raltegravir intensification on low-level residual viremia in HIV-infected patients on antiretroviral therapy: a randomized controlled trial. PLoS Med, 2010. 7(8).

[127] Buzon, M.J., et al., HIV-1 replication and immune dynamics are affected by raltegravir intensification of HAART-suppressed subjects. Nat Med, 2010. 16(4): p. 460-5.

[128] Josefsson, L., V. Dahl, and S. Palmer, Can HIV infection be eradicated through use of potent antiviral agents? Curr Opin Infect Dis, 2010. 23(6): p. 628-32.

[129] Davey, R.T., Jr., et al., HIV-1 and T cell dynamics after interruption of highly active antiretroviral therapy (HAART) in patients with a history of sustained viral suppression. Proc Natl Acad Sci U S A, 1999. 96(26): p. 15109-14.

[130] Chun, T.W., et al., Rebound of plasma viremia following cessation of antiretroviral therapy despite profoundly low levels of HIV reservoir: implications for eradication. AIDS, 2010. 24(18): p. 2803-8.

[131] Lori, F., et al., Control of SIV rebound through structured treatment interruptions during early infection. Science, 2000. 290(5496): p. 1591-3.

[132] Douek, D.C., et al., HIV preferentially infects HIV-specific CD4+ T cells. Nature, 2002. 417(6884): p. 95-8.

[133] Kawashima, Y., et al., Adaptation of HIV-1 to human leukocyte antigen class I. Nature, 2009. 458(7238): p. 641-5.

[134] Zhang, L., et al., Genetic characterization of rebounding HIV-1 after cessation of highly active antiretroviral therapy. J Clin Invest, 2000. 106(7): p. 839-45.

[135] Joos, B., et al., HIV rebounds from latently infected cells, rather than from continuing low-level replication. Proc Natl Acad Sci U S A, 2008. 105(43): p. 16725-30. 
[136] Chun, T.W., et al., Relationship between pre-existing viral reservoirs and the reemergence of plasma viremia after discontinuation of highly active anti-retroviral therapy. Nat Med, 2000. 6(7): p. 757-61.

[137] Dybul, M., et al., Genetic characterization of rebounding human immunodeficiency virus type 1 in plasma during multiple interruptions of highly active antiretroviral therapy. J Virol, 2003. 77(5): p. 3229-37.

[138] Kijak, G.H., et al., Origin of human immunodeficiency virus type 1 quasispecies emerging after antiretroviral treatment interruption in patients with therapeutic failure. J Virol, 2002. 76(14): p. 7000-9.

[139] Malaspina, A., et al., Human immunodeficiency virus type 1 bound to B cells: relationship to virus replicating in $\mathrm{CD} 4+\mathrm{T}$ cells and circulating in plasma. J Virol, 2002. 76(17): p. 8855-63.

[140] Lerner, P., et al., Gut mucosal viral reservoir in HIV infected patients is not the major source of rebound plasma viremia following HAART interruption. J Virol, 2011.

[141] Sharkey, M., et al., Episomal Viral cDNAs Identify a Reservoir That Fuels Viral Rebound after Treatment Interruption and That Contributes to Treatment Failure. PLoS Pathog, 2011. 7(2): p. e1001303.

[142] Imamichi, H., et al., Human immunodeficiency virus type 1 quasi species that rebound after discontinuation of highly active antiretroviral therapy are similar to the viral quasi species present before initiation of therapy. J Infect Dis, 2001. 183(1): p. 36-50.

[143] Geeraert, L., G. Kraus, and R.J. Pomerantz, Hide-and-seek: the challenge of viral persistence in HIV-1 infection. Annu Rev Med, 2008. 59: p. 487-501.

[144] Hutter, G., et al., Long-term control of HIV by CCR5 Delta32/Delta32 stem-cell transplantation. N Engl J Med, 2009. 360(7): p. 692-8.

[145] Kovacs, J.A., et al., Increases in CD4 T lymphocytes with intermittent courses of interleukin-2 in patients with human immunodeficiency virus infection. A preliminary study. N Engl J Med, 1995. 332(9): p. 567-75.

[146] Davey, R.T., Jr., et al., A randomized trial of high- versus low-dose subcutaneous interleukin-2 outpatient therapy for early human immunodeficiency virus type 1 infection. J Infect Dis, 1999. 179(4): p. 849-58.

[147] Kovacs, J.A., et al., Induction of prolonged survival of CD4+ T lymphocytes by intermittent IL-2 therapy in HIV-infected patients. J Clin Invest, 2005. 115(8): p. 2139-48.

[148] Simonelli, C., et al., Interleukin-2 in combination with zidovudine and didanosine is able to maintain high levels of CD4 cells and undetectable HIV viraemia. AIDS, 1998. 12(1): p. 112-3.

[149] Chun, T.W., et al., Effect of interleukin-2 on the pool of latently infected, resting CD4+ $\mathrm{T}$ cells in HIV-1-infected patients receiving highly active anti-retroviral therapy. Nat Med, 1999. 5(6): p. 651-5.

[150] Dybul, M., et al., Pilot study of the effects of intermittent interleukin-2 on human immunodeficiency virus (HIV)-specific immune responses in patients treated during recently acquired HIV infection. J Infect Dis, 2002. 185(1): p. 61-8.

[151] Kulkosky, J., et al., Intensification and stimulation therapy for human immunodeficiency virus type 1 reservoirs in infected persons receiving virally suppressive highly active antiretroviral therapy. J Infect Dis, 2002. 186(10): p. 1403-11. 
[152] Stellbrink, H.J., et al., Effects of interleukin-2 plus highly active antiretroviral therapy on HIV-1 replication and proviral DNA (COSMIC trial). AIDS, 2002. 16(11): p. 1479-87.

[153] Sereti, I., et al., In vivo expansion of CD4CD45RO-CD25 T cells expressing foxP3 in IL2-treated HIV-infected patients. J Clin Invest, 2005. 115(7): p. 1839-47.

[154] Grant, C., et al., Foxp3 represses retroviral transcription by targeting both NF-kappaB and CREB pathways. PLoS Pathog, 2006. 2(4): p. e33.

[155] Prins, J.M., et al., Immuno-activation with anti-CD3 and recombinant human IL-2 in HIV-1-infected patients on potent antiretroviral therapy. AIDS, 1999. 13(17): p. 2405-10.

[156] van Praag, R.M., et al., OKT3 and IL-2 treatment for purging of the latent HIV-1 reservoir in vivo results in selective long-lasting CD4+ $\mathrm{T}$ cell depletion. J Clin Immunol, 2001. 21(3): p. 218-26.

[157] Napolitano, L.A., et al., Increased production of IL-7 accompanies HIV-1-mediated Tcell depletion: implications for T-cell homeostasis. Nat Med, 2001. 7(1): p. 73-9.

[158] Llano, A., et al., Interleukin-7 in plasma correlates with CD4 T-cell depletion and may be associated with emergence of syncytium-inducing variants in human immunodeficiency virus type 1-positive individuals. J Virol, 2001. 75(21): p. 10319-25.

[159] Scripture-Adams, D.D., et al., Interleukin-7 induces expression of latent human immunodeficiency virus type 1 with minimal effects on T-cell phenotype. J Virol, 2002. 76(24): p. 13077-82.

[160] Lehrman, G., et al., Interleukin-7 induces HIV type 1 outgrowth from peripheral resting CD4+ T cells. J Acquir Immune Defic Syndr, 2004. 36(5): p. 1103-4.

[161] Wang, F.X., et al., IL-7 is a potent and proviral strain-specific inducer of latent HIV-1 cellular reservoirs of infected individuals on virally suppressive HAART. J Clin Invest, 2005. 115(1): p. 128-37.

[162] Kulkosky, J., et al., Prostratin: activation of latent HIV-1 expression suggests a potential inductive adjuvant therapy for HAART. Blood, 2001. 98(10): p. 3006-15.

[163] Kulkosky, J., et al., Expression of latent HAART-persistent HIV type 1 induced by novel cellular activating agents. AIDS Res Hum Retroviruses, 2004. 20(5): p. 497-505.

[164] Wender, P.A., J.M. Kee, and J.M. Warrington, Practical synthesis of prostratin, DPP, and their analogs, adjuvant leads against latent HIV. Science, 2008. 320(5876): p. 649-52.

[165] Williams, S.A., et al., Prostratin antagonizes HIV latency by activating NF-kappaB. J Biol Chem, 2004. 279(40): p. 42008-17.

[166] Biancotto, A., et al., Dual role of prostratin in inhibition of infection and reactivation of human immunodeficiency virus from latency in primary blood lymphocytes and lymphoid tissue. J Virol, 2004. 78(19): p. 10507-15.

[167] Gulakowski, R.J., et al., Antireplicative and anticytopathic activities of prostratin, a non-tumor-promoting phorbol ester, against human immunodeficiency virus (HIV). Antiviral Res, 1997. 33(2): p. 87-97.

[168] Korin, Y.D., et al., Effects of prostratin on T-cell activation and human immunodeficiency virus latency. J Virol, 2002. 76(16): p. 8118-23. 
[169] Zoumpourlis, V. and D.A. Spandidos, Hexamethylene bisacetamide stimulates the expression of human immunodeficiency virus long terminal repeat sequences in rat and human fibroblasts. Anticancer Drugs, 1992. 3(2): p. 163-7.

[170] Contreras, X., et al., HMBA releases P-TEFb from HEXIM1 and 7SK snRNA via PI3K/Akt and activates HIV transcription. PLoS Pathog, 2007. 3(10): p. 1459-69.

[171] Klichko, V., et al., Hexamethylbisacetamide remodels the human immunodeficiency virus type 1 (HIV-1) promoter and induces Tat-independent HIV-1 expression but blunts cell activation. J Virol, 2006. 80(9): p. 4570-9.

[172] Andreeff, M., et al., Hexamethylene bisacetamide in myelodysplastic syndrome and acute myelogenous leukemia: a phase II clinical trial with a differentiation-inducing agent. Blood, 1992. 80(10): p. 2604-9.

[173] Sung, T.L. and A.P. Rice, Effects of prostratin on Cyclin T1/P-TEFb function and the gene expression profile in primary resting CD4+ T cells. Retrovirology, 2006. 3: p. 66.

[174] Pearson, R., et al., Epigenetic silencing of human immunodeficiency virus (HIV) transcription by formation of restrictive chromatin structures at the viral long terminal repeat drives the progressive entry of HIV into latency. J Virol, 2008. 82(24): p. 12291-303.

[175] He, N., A.C. Pezda, and Q. Zhou, Modulation of a P-TEFb functional equilibrium for the global control of cell growth and differentiation. Mol Cell Biol, 2006. 26(19): p. 7068-76.

[176] Choudhary, S.K., N.M. Archin, and D.M. Margolis, Hexamethylbisacetamide and disruption of human immunodeficiency virus type 1 latency in CD4(+) T cells. J Infect Dis, 2008. 197(8): p. 1162-70.

[177] Cho, J., M.E. Parks, and P.B. Dervan, Cyclic polyamides for recognition in the minor groove of DNA. Proc Natl Acad Sci U S A, 1995. 92(22): p. 10389-92.

[178] Coull, J.J., et al., Targeted derepression of the human immunodeficiency virus type 1 long terminal repeat by pyrrole-imidazole polyamides. J Virol, 2002. 76(23): p. 12349-54.

[179] Ylisastigui, L., et al., Polyamides reveal a role for repression in latency within resting T cells of HIV-infected donors. J Infect Dis, 2004. 190(8): p. 1429-37.

[180] Archin, N.M. and D.M. Margolis, Attacking latent HIV provirus: from mechanism to therapeutic strategies. Curr Opin HIV AIDS, 2006. 1(2): p. 134-40.

[181] Verdin, E., P. Paras, Jr., and C. Van Lint, Chromatin disruption in the promoter of human immunodeficiency virus type 1 during transcriptional activation. EMBO J, 1993. 12(8): p. 3249-59.

[182] Van Lint, C., et al., Transcriptional activation and chromatin remodeling of the HIV-1 promoter in response to histone acetylation. EMBO J, 1996. 15(5): p. 1112-20.

[183] Quivy, V., et al., Synergistic activation of human immunodeficiency virus type 1 promoter activity by NF-kappaB and inhibitors of deacetylases: potential perspectives for the development of therapeutic strategies. J Virol, 2002. 76(21): p. 11091-103.

[184] Moog, C., et al., Sodium valproate, an anticonvulsant drug, stimulates human immunodeficiency virus type 1 replication independently of glutathione levels. J Gen Virol, 1996. 77 ( Pt 9): p. 1993-9. 
[185] Witvrouw, M., et al., Cell type-dependent effect of sodium valproate on human immunodeficiency virus type 1 replication in vitro. AIDS Res Hum Retroviruses, 1997. 13(2): p. 187-92.

[186] Ylisastigui, L., et al., Coaxing HIV-1 from resting CD4 T cells: histone deacetylase inhibition allows latent viral expression. AIDS, 2004. 18(8): p. 1101-8.

[187] Lehrman, G., et al., Depletion of latent HIV-1 infection in vivo: a proof-of-concept study. Lancet, 2005. 366(9485): p. 549-55.

[188] Archin, N.M., et al., Valproic acid without intensified antiviral therapy has limited impact on persistent HIV infection of resting CD4+ T cells. AIDS, 2008. 22(10): p. 1131-5.

[189] Siliciano, J.D., et al., Stability of the latent reservoir for HIV-1 in patients receiving valproic acid. J Infect Dis, 2007. 195(6): p. 833-6.

[190] Sagot-Lerolle, N., et al., Prolonged valproic acid treatment does not reduce the size of latent HIV reservoir. AIDS, 2008. 22(10): p. 1125-9.

[191] Archin, N.M., et al., Antiretroviral intensification and valproic acid lack sustained effect on residual HIV-1 viremia or resting CD4+ cell infection. PLoS One, 2010. 5(2): p. e9390.

[192] Perez, M., et al., Bryostatin-1 Synergizes with Histone Deacetylase Inhibitors to Reactivate HIV-1 from Latency. Curr HIV Res, 2010. 8(6): p. 418-29.

[193] Archin, N.M., et al., Expression of latent HIV induced by the potent HDAC inhibitor suberoylanilide hydroxamic acid. AIDS Res Hum Retroviruses, 2009. 25(2): p. 207-12.

[194] Contreras, X., et al., Suberoylanilide hydroxamic acid reactivates HIV from latently infected cells. J Biol Chem, 2009. 284(11): p. 6782-9.

[195] Marks, P.A. and R. Breslow, Dimethyl sulfoxide to vorinostat: development of this histone deacetylase inhibitor as an anticancer drug. Nat Biotechnol, 2007. 25(1): p. 84-90.

[196] Shehu-Xhilaga, M., et al., The novel histone deacetylase inhibitors metacept-1 and metacept-3 potently increase HIV-1 transcription in latently infected cells. AIDS, 2009. 23(15): p. 2047-50.

[197] Yin, H., et al., Histonedeacetylase inhibitor Oxamflatin increase HIV-1 transcription by inducing histone modification in latently infected cells. Mol Biol Rep, 2010.

[198] Victoriano, A.F., et al., Novel histone deacetylase inhibitor NCH-51 activates latent HIV-1 gene expression. FEBS Lett, 2011.

[199] Blazkova, J., et al., CpG methylation controls reactivation of HIV from latency. PLoS Pathog, 2009. 5(8): p. e1000554.

[200] Kauder, S.E., et al., Epigenetic regulation of HIV-1 latency by cytosine methylation. PLoS Pathog, 2009. 5(6): p. e1000495.

[201] Yang, H.C., et al., Small-molecule screening using a human primary cell model of HIV latency identifies compounds that reverse latency without cellular activation. J Clin Invest, 2009. 119(11): p. 3473-86.

[202] Reuse, S., et al., Synergistic activation of HIV-1 expression by deacetylase inhibitors and prostratin: implications for treatment of latent infection. PLoS One, 2009. 4(6): p. e6093.

[203] Burnett, J.C., et al., Combinatorial latency reactivation for HIV-1 subtypes and variants. J Virol, 2010. 84(12): p. 5958-74. 
[204] Kennedy, P.E., et al., Anti-HIV-1 immunotoxin 3B3(Fv)-PE38: enhanced potency against clinical isolates in human PBMCs and macrophages, and negligible hepatotoxicity in macaques. J Leukoc Biol, 2006. 80(5): p. 1175-82.

[205] Saavedra-Lozano, J., et al., An anti-CD45RO immunotoxin kills HIV-latently infected cells from individuals on HAART with little effect on CD8 memory. Proc Natl Acad Sci U S A, 2004. 101(8): p. 2494-9.

[206] Huisman, M.T., J.W. Smit, and A.H. Schinkel, Significance of P-glycoprotein for the pharmacology and clinical use of HIV protease inhibitors. AIDS, 2000. 14(3): p. 237-42.

[207] Rao, K.S., et al., TAT-conjugated nanoparticles for the CNS delivery of anti-HIV drugs. Biomaterials, 2008. 29(33): p. 4429-38.

[208] Mahajan, S.D., et al., Enhancing the delivery of anti retroviral drug "Saquinavir" across the blood brain barrier using nanoparticles. Curr HIV Res, 2010. 8(5): p. 396-404.

[209] O'Brien, M.C., et al., HIV-1 expression induced by anti-cancer agents in latently HIV-1infected ACH2 cells. Biochem Biophys Res Commun, 1995. 207(3): p. 903-9.

[210] Lindkvist, A., et al., Reduction of the HIV-1 reservoir in resting CD4+ T-lymphocytes by high dosage intravenous immunoglobulin treatment: a proof-of-concept study. AIDS Res Ther, 2009. 6: p. 15.

[211] Margolis, D.M., Eradication Therapies for HIV Infection: Time to Begin Again. AIDS Res Hum Retroviruses, 2011. 27(4): p. 347-53. 


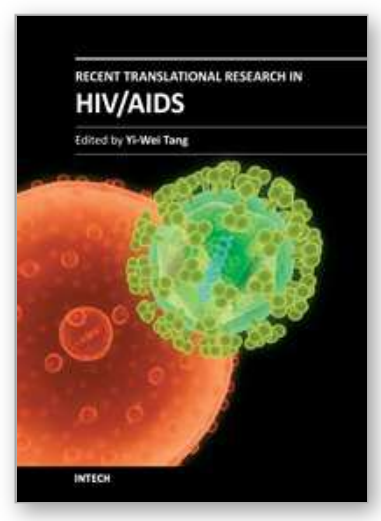

\author{
Recent Translational Research in HIV/AIDS \\ Edited by Prof. Yi-Wei Tang
}

ISBN 978-953-307-719-2

Hard cover, 564 pages

Publisher InTech

Published online 02, November, 2011

Published in print edition November, 2011

The collective efforts of HIV/AIDS research scientists from over 16 countries in the world are included in the book. This 27-chapter Open Access book well covers HIV/AIDS translational researches on pathogenesis, diagnosis, treatment, prevention, and also those beyond conventional fields. These are by no means inclusive, but they do offer a good foundation for the development of clinical patient care. The translational model forms the basis for progressing HIV/AIDS clinical research. When linked to the care of the patients, translational researches should result in a direct benefit for HIV/AIDS patients.

\title{
How to reference
}

In order to correctly reference this scholarly work, feel free to copy and paste the following:

James Williams, Sarah Fidler and John Frater (2011). Characterisation, Evaluation and Clinical Significance of Latent HIV-1 Reservoirs and Therapeutic Strategies for HIV Eradication, Recent Translational Research in HIV/AIDS, Prof. Yi-Wei Tang (Ed.), ISBN: 978-953-307-719-2, InTech, Available from:

http://www.intechopen.com/books/recent-translational-research-in-hiv-aids/characterisation-evaluation-andclinical-significance-of-latent-hiv-1-reservoirs-and-therapeutic-str

\section{INTECH}

open science | open minds

\section{InTech Europe}

University Campus STeP Ri

Slavka Krautzeka 83/A

51000 Rijeka, Croatia

Phone: +385 (51) 770447

Fax: +385 (51) 686166

www.intechopen.com

\section{InTech China}

Unit 405, Office Block, Hotel Equatorial Shanghai

No.65, Yan An Road (West), Shanghai, 200040, China

中国上海市延安西路65号上海国际贵都大饭店办公楼405单元

Phone: +86-21-62489820

Fax: $+86-21-62489821$ 
(C) 2011 The Author(s). Licensee IntechOpen. This is an open access article distributed under the terms of the Creative Commons Attribution 3.0 License, which permits unrestricted use, distribution, and reproduction in any medium, provided the original work is properly cited. 